The University of San Francisco

USF Scholarship: a digital repository @ Gleeson Library |

Geschke Center

2011

\title{
Quantifying the Impact of Gene Flow on Phenotype-Environment Mismatch: A Demonstration with the Scarlet Monkeyflower Mimulus cardinalis
}

John R. Paul

University of San Francisco, jrpaul@usfca.edu

Seema N. Sheth

Amy L. Angert

Follow this and additional works at: http://repository.usfca.edu/biol_fac

Part of the Biology Commons

\section{Recommended Citation}

Paul JR, Sheth SN, Angert AL. Quantifying the impact of gene flow on phenotype-environment mismatch: a demonstration with the scarlet monkeyflower Mimulus cardinalis. Am Nat. 2011 Oct; 178 Suppl 1:S62-79.

This Article is brought to you for free and open access by the Biology at USF Scholarship: a digital repository @ Gleeson Library | Geschke Center. It has been accepted for inclusion in Biology Faculty Publications by an authorized administrator of USF Scholarship: a digital repository @ Gleeson Library | Geschke Center. For more information, please contact repository@usfca.edu. 


\title{
Quantifying the Impact of Gene Flow on Phenotype- Environment Mismatch: A Demonstration with the Scarlet Monkeyflower Mimulus cardinalis
}

\author{
John R. Paul, ${ }^{1, \star}$ Seema N. Sheth, ${ }^{1,2}$ and Amy L. Angert ${ }^{1,2}$ \\ 1. Department of Biology, Colorado State University, Fort Collins, Colorado 80523; 2. Graduate Degree Program in Ecology, Colorado \\ State University, Fort Collins, Colorado 80523 \\ Online enhancement: zip file.
}

\begin{abstract}
AвSTRACT: Geographic range margins offer testing grounds for limits to adaptation. If range limits are concordant with niche limits, range expansions require the evolution of new phenotypes that can maintain populations beyond current range margins. However, many species' range margins appear static over time, suggesting limits on the ability of marginal populations to evolve appropriate phenotypes. A potential explanation is the swamping gene flow hypothesis, which posits that asymmetrical gene flow from large, well-adapted central populations prevents marginal populations from locally adapting. We present an empirical framework for combining gene flow, environment, and fitness-related phenotypes to infer the potential for maladaptation, and we demonstrate its application using the scarlet monkeyflower Mimulus cardinalis. We grew individuals sampled from populations on a latitudinal transect under varied temperatures and determined the phenotypic deviation (PD), the mismatch between phenotype and local environment. We inferred gene flow among populations and predicted that populations receiving the most temperature- or latitude-weighted immigration would show the greatest PD and that these populations were likely marginal. We found asymmetrical gene flow from central to marginal populations. Populations with more latitude-weighted immigration had significantly greater PD but were not necessarily marginal. Gene flow may limit local adaptation in this species, but swamping gene flow is unlikely to explain its northern range limit.
\end{abstract}

Keywords: adaptation, geographic range, population genetics, range limits, relative growth rate.

\section{Introduction}

The geographic ranges of some species span continents while others are limited to only a handful of locations, yet every species has a geographic distribution that is circumscribed by range boundaries. Explaining why individuals occur at a species' geographic range margin yet do not persist only a short distance beyond the margin is an im-

* Corresponding author; e-mail: johnrpaul@gmail.com.

Am. Nat. 2011. Vol. 178, pp. S62-S79. (C) 2011 by The University of Chicago. 0003-0147/2011/178S1-52348\$15.00. All rights reserved.

DOI: $10.1086 / 661781$ portant and long-standing problem in evolutionary ecology (Mayr 1963; Antonovics 1976). In some cases, presentday range limits may be transient fronts that arise as a result of dispersal limitation and temporal environmental variation (Katinas and Crisci 2008; Paul and Tonsor 2008; Svenning et al. 2008; Paul et al. 2009). In other cases, range boundaries appear to be at ecological equilibrium and reflect persistent niche limitation. For example, experiments that translocate individuals beyond range boundaries show that many species cannot survive or reproduce beyond their ranges (Clausen et al. 1948; Angert and Schemske 2005; Geber and Eckhart 2005; Griffith and Watson 2006). Range boundaries are frequently associated with limiting abiotic variables such as temperature (Root 1988; Cumming 2002), biotic factors such as competitors (Terborgh and Weske 1975; Bullock et al. 2000), or complex interactions between biotic and abiotic variables (Randall 1982; Taniguchi and Nakano 2000). However, even a mechanistic understanding of the relationship between environmental variables, fitness, and distribution does not fully explain the apparent stasis of some populations at range margins over evolutionary time. If a species is maladapted to conditions beyond its range margin, why do phenotypes that would permit range expansion fail to evolve? Range margins provide a unique and tractable venue to explore the larger problem of understanding what factors limit adaptation (Bridle and Vines 2007).

A strong theoretical tradition has led to the exploration of different mechanisms that can create evolutionarily stable range limits, at least under idealized conditions (Holt and Keitt 2005; Sexton et al. 2009; Holt and Barfield 2011). First, ecological dynamics may pose long-term evolutionary constraints on marginal populations. For example, resource competition along environmental gradients can favor specialization to different segments of a resource spectrum and hence restrict the ranges of competitors (Price and Kirkpatrick 2009; Price et al. 2011). Also, 
extinction-recolonization dynamics in a metapopulation system may periodically reset the clock on local adaptation to the range margin (Holt and Keitt 2000). Another class of hypotheses focuses on genetic variation (Antonovics 1976; Blows and Hoffman 2005; Eckert et al. 2008; Kawecki 2008). Marginal populations may lack genetic variation in traits that are under selection at the range margin for a number of reasons, including depletion by persistent strong selection, genetic bottlenecks at the margin, founder events during range expansion, and inbreeding in small peripheral populations. Further, marginal populations may harbor moderate genetic variation at neutral genetic markers or for particular phenotypic traits yet lack multivariate genetic variation in dimensions that are necessary for range expansion (Bradshaw 1991; Blows and Hoffman 2005).

Here we focus on another class of models that we will broadly refer to as the swamping gene flow hypothesis (Haldane 1956; Kirkpatrick and Barton 1997; Holt et al. 2005). In the context of range limits, this hypothesis is exemplified by the model outlined by Kirkpatrick and Barton (1997), in which gene flow from large, well-adapted central populations restricts the ability of marginal populations to locally adapt and, hence, expand beyond a species' current geographic range limit. This basic model has subsequently been modified and expanded to incorporate competitive interactions (Case and Taper 2000), variation in genetic variance among populations (Barton 2001), the influence of dispersal barriers (Barton 2001; Goldberg and Lande 2007), and changes in genetic variation over time (Alleaume-Benharira et al. 2006). These models begin with an environmental gradient that affects fitness. Local demography is linked to selection such that mismatch between phenotypes and local environmental conditions depresses local abundance. When environmental gradients are sufficiently steep or dispersal is sufficiently high, gene flow from large and well-adapted central populations introduces maladaptive alleles into edge populations and pushes edge populations away from local fitness optima until populations are so maladapted that they are unable to persist. Similar outcomes are predicted by models of evolution between discrete source (e.g., range center) and sink (e.g., range margin) habitat patches (Holt et al. 2005; Holt and Barfield 2011). Key to these models is the impact of swamping gene flow on local demography, whereby the influx of maladapted genotypes results in marginal sink populations that have negative population growth rates and low effective population sizes. Thus, marginal populations might be susceptible to losing genetic variation to genetic drift (Vucetich and Waite 2003) and becoming genetically differentiated as a result of random sampling (due to extinction and recolonization events [Lennon et al. 1997; Holt and Keitt 2005]). On the contrary, gene flow may actually facilitate local adaption and increase the fitness of marginal populations, if these populations are genetically depauperate (Holt and Gomulkiewicz 1997; Barton 2001; Holt 2003; Holt et al. 2004; Alleaume-Benharira et al. 2006). The main assumptions of the swamping gene flow hypothesis of range limits are that (1) a species occupies a gradient of environmental conditions from the range center to the margin, with (2) a concomitant selection gradient that favors clinal phenotypic differentiation from the range center to the margin, and there is (3) persistent asymmetrical gene flow from central to marginal populations. While sound in theory, the swamping gene flow hypothesis of range limits has seldom been tested empirically, and the realism of the proposed mechanism can be difficult to envision for wide-ranging species with fragmented and idiosyncratic distributions.

One challenge of studying the effects of swamping gene flow in natural populations is quantifying the impact of gene flow on the phenotypes, absolute fitness, and local adaptation of recipient populations. Ideally, we could construct an adaptive landscape that displays the topography of fitness as a function of phenotypes. In the context of geographic range limits, we want to see how this adaptive landscape changes with environment (e.g., from the center to the edge). Then, given a series of adaptive landscapes from the center to the range edge, we could determine which phenotypes are optimal in a particular environment, where a local population is relative to the optimum phenotype (fig. 1A), and whether the degree of mismatch between the optimum phenotype and the local phenotype is influenced by gene flow. In the absence of knowledge of a true fitness landscape, one approach is to quantify some metric of phenotypes in common garden environments and then relate population-level phenotypes to local (population-specific) environmental conditions. The degree of mismatch between phenotypes and environment, which we term the phenotypic deviation (PD), can be interpreted as a metric of potential maladaptation (fig. $1 B$ ). As such, we may expect populations that receive more gene flow to show greater phenotypic deviation from the local phenotypic optimum. We can use a measure of the local environment, such as a growing season temperature, as a surrogate for the true unknown optima, and we expect the populations that receive more maladaptive gene flow to show greater phenotypic deviation from the local environmental measure. However, even if a population receives substantial gene flow from another population, it does not necessarily mean that maladaptive alleles are being introduced into the recipient population. Not all gene flow is equivalent, since there should be a greater probability of introducing maladaptive alleles if gene-exchanging populations differ markedly in their selective regimes and expected phenotypic optima. Hence, gene flow from 
A

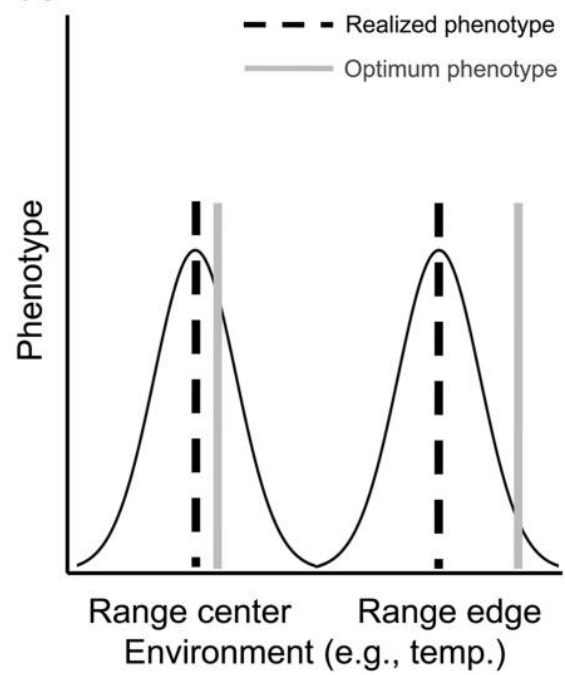

B

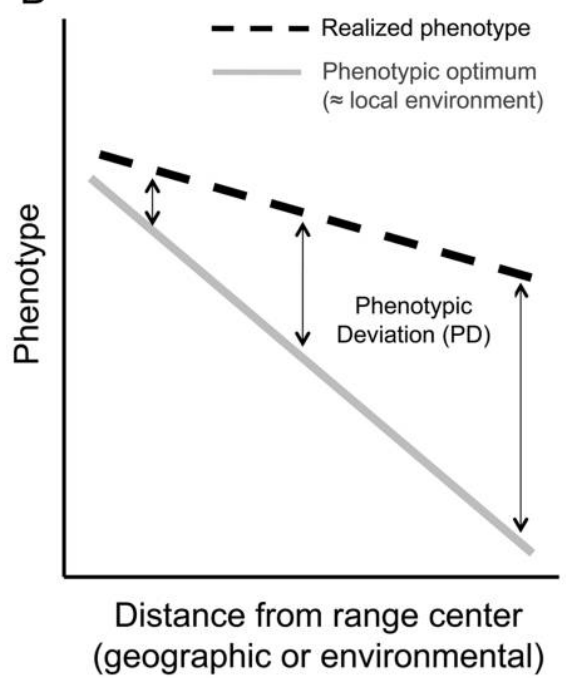

Figure 1: Model depicting the relationship between realized phenotypes and their expected phenotypic optima, based on an unknown (true) fitness landscape. A, Realized phenotypes may not perfectly match optimal phenotypes in a particular environment, and this mismatch may increase toward the range margin. $B$, Expected relationship between a local environmental optimum and the realized phenotypic optimum, if phenotype-environment mismatch increases toward the range margin. The difference between these two metrics is the phenotypic deviation.

donor populations that are physically or environmentally distant from recipient populations might introduce maladaptive genotypes to recipient populations, and the farther away a donor population is (in terms of spatial or environmental distance), the more likely that these populations might include maladaptive alleles that would be unfit in the recipient population. Thus, populations with a greater influx of environmentally or spatially distant migrants should have greater phenotypic mismatch to local environments. Considering geographic ranges, if maladaptive gene flow is important, we expect phenotypic clines of shallower slope than the environmental gradient across the geographic range, with an increasing mismatch between phenotypes and local environmental conditions moving toward the range margin (fig. $1 B$ ).

Here, we demonstrate how to employ the framework described above to investigate the swamping gene flow hypothesis of range limits by examining the relationship between gene flow and phenotypic deviation across a geographic range. We examined the northern geographic range limit of the perennial herb Mimulus cardinalis (Phyrmaceae). We integrated genetic, phenotypic, and climate data from 13 populations spanning a latitudinal gradient that encompasses the northern half of the known geographic range of $M$. cardinalis. Our genetic data consist of DNA sequences from six nuclear intronic loci sampled from a total of $\sim 120$ individuals, collected from each pop- ulation along our latitudinal sampling gradient. We used haplotype frequencies to calculate population-level genetic diversity, differentiation and rates of contemporary gene flow, and sequence data to infer rates of historical gene flow under a coalescent framework. We calculated the degree of genetic differentiation among populations and regions using $F_{\mathrm{ST}}$ values and an analysis of molecular variance (AMOVA) and examined the relationship between genetic and geographic distances (isolation by distance; [IBD]). Given the demonstrated importance of temperature to the growth and reproduction of $M$. cardinalis (Decker 1958; Hiesey et al. 1971; Angert 2006; Angert et al. 2008), we focused our phenotypic investigation on growth responses to temperature. We propagated clones from 12 of these populations and exposed them to varied temperature regimes to estimate the temperature for maximum growth. We then calculated the degree of mismatch between estimates of local growing season temperature and growth phenotype for a given population. To incorporate environmental differences among populations into gene flow estimates, we weighted the migration estimates on the basis of the difference between donor and recipient populations in their latitude or temperature. We made the following predictions: (1) historical and contemporary rates of gene flow are asymmetrically biased from central (southern) to marginal (northern) populations; (2) temperature optima for growth decrease with latitude, yet not 
as rapidly as environmental temperature decreases with latitude across the geographic range of $M$. cardinalis; hence, (3) phenotypic deviation increases with latitude from the center to the margin of the range, and (4) rates of latitude-weighted immigration and temperatureweighted immigration explain variation in phenotypic deviation across the geographic range. Finally, if marginal populations do represent chronic sink populations, we expect that (5) population genetic diversity metrics will decrease from the range center to the range margin (with increasing latitude).

\section{Methods \\ Study System}

Mimulus cardinalis is a perennial herb that grows along seeps and stream banks from southern Oregon to northern Baja California and from coastal California east to the Sierra Nevada Mountains (Hiesey et al. 1971; Hickman 1993; fig. 2). Although herbarium records of M. cardinalis are present in the southwestern United States and central Mexico, these disjunct populations have crossing barriers with Californian populations and cluster into well-supported sister clades (Hiesey et al. 1971; Beardsley et al. 2003). In California, M. cardinalis occurs from sea level to 2,400 m (Hickman 1993), although the elevation limits of the species decrease with increasing latitude (Ramsey et al. 2003).

\section{Sample Collection}

We collected leaf tissue and seeds from a latitudinal gradient from the southern Sierra Nevada Mountains to the Willamette Valley of Oregon (table 1; fig. 2). The latitudinal range center point lies between $36.876^{\circ} \mathrm{N}$ and $37.487^{\circ} \mathrm{N}$, depending on the method of calculation (table A1 [app. A-F are available in a zip file in the online edition of the American Naturalist]). Because, biologically, the range center encompasses a set of populations nested in a particular region, we defined populations within the central $50 \%$ of the range as central and populations in the northern $25 \%$ of the latitudinal range as marginal. The northernmost population of record is at $44.052^{\circ} \mathrm{N}$, although we were unable to locate plants at or beyond this locality in July 2007 and June 2010. The sampling transect began just south of the range center point and ended near the northernmost recorded population. The 13 locations used in this article represent 13 river drainages encompassed by our sampling transect (fig. 2). Leaf tissue was collected from 5-20 individuals in each population, with a minimum distance of $\sim 2 \mathrm{~m}$ between individuals to avoid collecting multiple ramets of the same genet. We collected

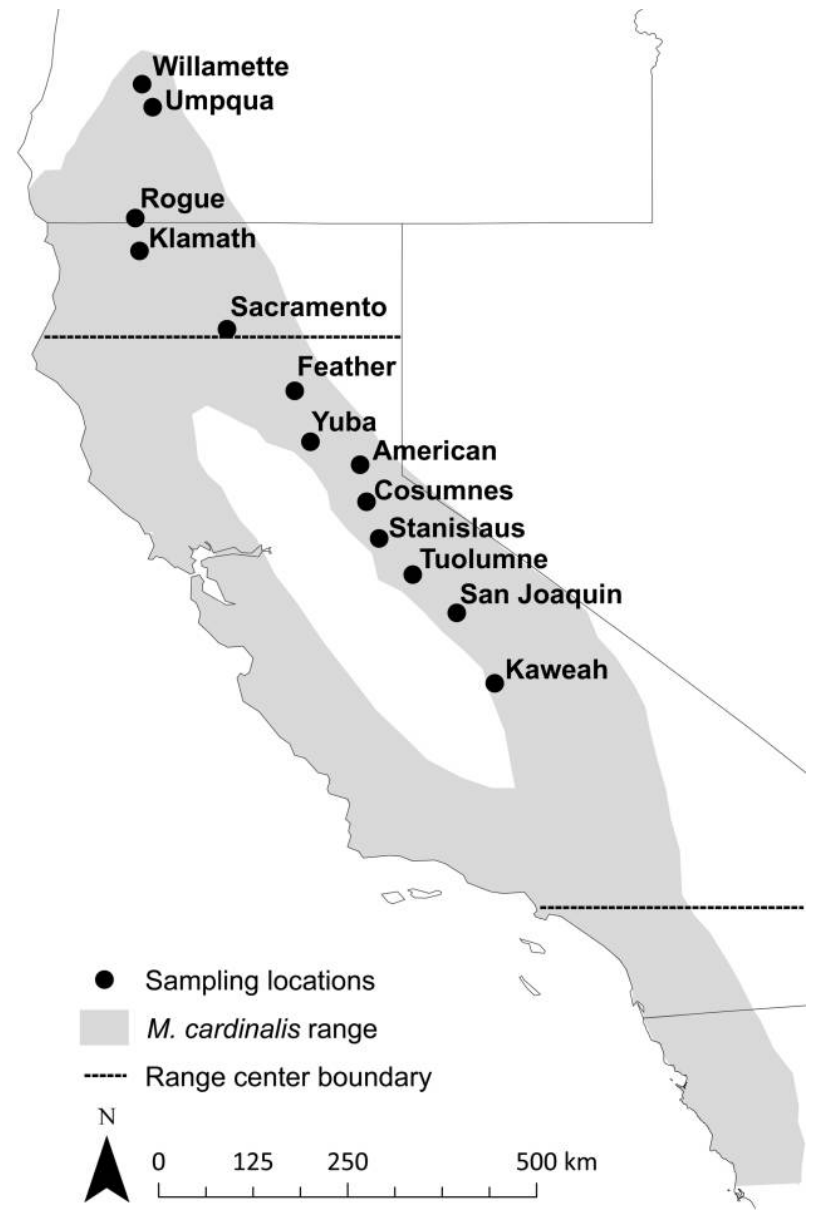

Figure 2: Mimulus cardinalis range map (modified from Hiesey et al. 1971) showing range center zone (defined as the center $50 \%$ of the known latitudinal range) and sampling locations. Individuals of M. cardinalis from Sacramento were used only in genetic analyses. Individuals from San Joaquin and Cosumnes were used only in some genetic analyses because of small sample size.

$3-5$ young leaves in small plastic bags with $\sim 0.25 \mathrm{~g}$ silica gel. When possible, we also collected fruits from the same individuals and stored the fruits in paper coin envelopes. Seeds were grown in the greenhouses at Colorado State University for phenotypic measurements, described below. We also collected leaf material for DNA extraction from some greenhouse-reared plants whose mothers were not already represented in leaf tissue collections, using the same silica gel protocol as above, in populations where we could not find sufficient quality or quantity of leaf material.

\section{Genetic Data}

DNA Extraction, Amplification, and Sequencing. We extracted DNA following the protocol of Alexander et al. 
Table 1: Data for Mimulus cardinalis populations

\begin{tabular}{lcccccc}
\hline & & & & & \multicolumn{2}{c}{$N$} \\
\cline { 3 - 6 } Population & Latitude $\left({ }^{\circ} \mathrm{N}\right)$ & Longitude $\left({ }^{\circ} \mathrm{W}\right)$ & Elevation $(\mathrm{m})$ & July $T_{\max }\left({ }^{\circ} \mathrm{C}\right)$ & Genotypic & Phenotypic $^{\mathrm{a}}$ \\
\hline Kaweah & 36.521 & -118.894 & 465 & 37.1 & 7 & 7 \\
San Joaquin & 37.359 & -119.345 & 1,141 & 31.4 & 2 & 9 \\
Tuolumne & 37.815 & -119.866 & 1,320 & 29.1 & 13 & 11 \\
Stanislaus & 38.245 & -120.266 & 1,269 & 29.1 & 10 & 9 \\
Cosumnes & 38.680 & -120.417 & 1,350 & 30.4 & 2 & 9 \\
American & 39.122 & -120.492 & 1,490 & 26.2 & 10 & 9 \\
Yuba & 39.394 & -121.083 & 425 & 33.5 & 10 & 8 \\
Feather & 40.000 & -121.270 & 620 & 31.6 & 10 & 9 \\
Sacramento & 40.734 & -122.073 & 342 & 35.4 & 7 & 0 \\
Klamath & 41.665 & -123.113 & 614 & 29.5 & 10 & 8 \\
Rogue & 42.055 & -123.164 & 689 & 25.5 & 7 & 6 \\
Umpqua & 43.375 & -122.957 & 323 & 27.9 & 9 & 11 \\
Willamette & 43.649 & -123.084 & 256 & 26.3 & 10 & 10 \\
\hline
\end{tabular}

a Used for cloning.

(2007), which uses a reciprocating saw and steel beads to pulverize leaf tissue and silica columns to recover DNA before elution in $10 \mathrm{mM}$ Tris solution. We amplified 10 exon-primed, intron-crossing nuclear loci using primer sequences developed for Mimulus lewisii and prescreened for polymorphism in M. cardinalis by T. Bradshaw (University of Washington). Of these 10 loci, we chose six loci that consistently amplified across all our sample populations and that yielded high quality and consistent chromatograms. The six loci varied in length from 319 to 540 base pairs (table 1) and are found on four different linkage groups, putatively four out of eight chromosomes (linkage group; GenBank accession numbers): MISTS5073 (5; JN161706-JN161815), MlSTS5164 (7; JN161165JN161272), MISTS5334 (1; JN161273-JN161376), MlSTS5525 (6; JN161377-JN161486), MISTS5536 (5; JN161487-JN161596), MlSTS5551 (7; JN161597JN161705). Primer sequences and further information on these markers are available at the MIMULUS project Web site (http://www.mimulusevolution.org).

All polymerase chain reaction (PCR) was conducted using two Eppendorf Mastercycler EP thermocyclers (Eppendorf North America, Westbury, NY). Reactions consisted of $15.4 \mu \mathrm{L}$ double-distilled $\mathrm{H}_{2} \mathrm{O}, 2.0 \mu \mathrm{L} 10 \times$ buffer (New England Biolabs [NEB], Ipswich, MA), 1.0 $\mu$ L bovine serum albumin (NEB), $0.20 \mu \mathrm{L}$ deoxyribonucleotide triphosphate (10 $\mu \mathrm{M}$; Integrated DNA Technologies [IDT], Coralville, IA), $0.2 \mu \mathrm{L}$ forward primer (0.10 uM; IDT), 0.2 $\mu \mathrm{L}$ reverse primer $(0.10 \mathrm{uM}$; IDT), $0.04 \mu \mathrm{L}$ Taq polymerase (NEB), and $1.00 \mu \mathrm{L}$ template DNA in a final volume of $20 \mu \mathrm{L}$. The basic thermocycler protocol was 1 cycle of $94.0^{\circ} \mathrm{C}$ for $3 \mathrm{~min}$, followed by 10 cycles of $30 \mathrm{~s}$ at $94.0^{\circ} \mathrm{C}$, $30 \mathrm{~s}$ at $62.0^{\circ} \mathrm{C}$, and $45 \mathrm{~s}$ at $72.0^{\circ} \mathrm{C}$, with a step down of $1^{\circ} \mathrm{C}$ for each step $\left(62.0^{\circ}-52.0^{\circ} \mathrm{C}\right)$, followed by 30 steps of
$30 \mathrm{~s}$ at $94.0^{\circ} \mathrm{C}, 30 \mathrm{~s}$ at $48.0^{\circ} \mathrm{C}$, and $45 \mathrm{~s}$ at $72.0^{\circ} \mathrm{C}$. Protocols were modified when necessary to improve amplification from specific individuals for specific loci. PCR products were visualized on 1.0\% agarose gels using GelRed (Biotium, Hayward, CA) and a ultraviolet light in a BioRad Universal Hood II (BioRad, Hercules, CA). Successful PCR products were cleaned using a basic exonuclease I-shrimp alkaline phosphatase protocol and sent to the DNA Sequencing Facility at the University of Chicago Cancer Research Center, which uses ABI 3730XL and 3130 DNA sequencers. We ordered forward reads of all sequences, and the vast majority yielded high-quality, unambiguous chromatograms. We ordered reverse reads of sequences that did not have high-quality chromatograms ( $~ 5 \%$ of all sequences) or had heterozygous indels ( $\sim 5 \%$ of all sequences). We also resequenced 24 reads from new PCR amplifications in order to check the reliability of our initial reads ( $\sim 4 \%$ of sequences for each locus). Our estimated error rate on a per nucleotide basis was $<0.001 \%$.

Sequence Data Preparation. We aligned DNA sequences using the MUSCLE algorithm in the program Geneious (ver. 4.8; Drummond et al. 2009). Alignments were straightforward, with very few indels. To call heterozygous states, we used the sequencing chromatograms to assign International Union of Pure and Applied Chemistry ambiguity codes to any sites with clear double peaks. All polymorphic alignment columns were manually inspected and edited to make sure the site was truly polymorphic and that all heterozygous sites were properly coded. If a site was deemed ambiguous after inspection (e.g., if the potential heterozygote signal peak was not sufficiently higher than neighboring background noise), the site was coded as N. Final alignments were imported into DnaSP 
(Librado and Rozas 2009) to phase diploid sequences into haploid sequences, using the module Phase (ver. 2.1; Stephens et al. 2001).

Analysis of Genetic Structure. We tested for deviations from Hardy-Weinberg equilibrium using 1,000 permutations in the program Arlequin (ver. 3.5; Excoffier et al. 2005). Although we found occasional departures in certain locus by population combinations ( 14 out of 83 tests), there was no consistent evidence that certain loci or populations persistently deviated from Hardy-Weinberg equilibrium (table B1).

Haplotype frequencies were used to calculate $F_{\mathrm{ST}}$ in Arlequin (Excoffier et al. 2005). To test for range-wide genetic differentiation, we used an AMOVA, implemented in the program Arlequin (Excoffier et al. 2005). We included a regional term to group populations into central (within the center $50 \%$ of the latitudinal range of $M$. cardinalis) and marginal (north of the defined center; for further explanation, see table A1). We also tested for IBD using a Mantel test of $\log _{10}$ (genetic distance, $F_{\mathrm{ST}}$ ) versus $\log _{10}$ (geographic distance, great circle distance), using the IBD Web Service (Jensen et al. 2005).

Analysis of DNA Polymorphism. To test the prediction of a reduction in genetic diversity from the range center to the range margin, we calculated the number of segregating sites $(S)$ and nucleotide diversity $(\pi)$ for sequences of each locus, grouped by population (sampling location) in DnaSP. We averaged these values across loci to obtain overall estimates. To assess the distribution of private haplotypes and measure haplotype richness among populations, we used the program ADZE (Allelic Diversity Analyzer; Szpiech et al. 2008), which uses rarefaction to account for variation in sample sizes among populations. We used regression to test for molecular diversity by latitude relationships.

Estimating Contemporary Migration Rates. We used the program BayesAss + (ver. 1.3; Wilson and Rannala 2003) to estimate rates of migration over the past few generations to test the prediction of asymmetrical gene flow from central to marginal populations. BayesAss is a Bayesian clustering algorithm that uses Markov chain Monte Carlo (MCMC) sampling to make inferences about levels of migration and population inbreeding using diploid neutral genetic markers. We used our haplotype frequency data set to infer a migration matrix among 11 of our putative populations (all populations with genotypic $N \geq 7$; table 1). We used the following settings: number of iterations, 5,000,000; sampling frequency, 2,000; length of burn-in, 999,999; $\delta$ allele, $0.15 ; \delta$ migration, $0.15 ; \delta F, 0.15$. BayesAss is one of few programs that can infer asymmetrical mi- gration rates. However, some BayesAss runs can have poor MCMC sampling, where values get stuck near the bounds of the priors (Faubet et al. 2007). Hence, following the protocol suggested by Faubet et al. (2007), we ran BayesAss 10 times under identical conditions but with different random number seeds. We then calculated the Bayesian deviance of the assignments and used the run with the lowest Bayesian deviance for further analyses (Faubet et al. 2007). We determined whether MCMC chains had reached a stable state by examining the changes in log-likelihood values across iterations.

Estimating Historical Migration Rates. We used the program Migrate-N (ver. 3.1.6; Beerli and Felsenstein 1999) to estimate historical rates of migration and genetic diversity ( $\theta$ values) to test the prediction of asymmetrical gene flow from central to marginal populations. Migrate$\mathrm{N}$ is a coalescent genealogy sampler that uses MCMC sampling under a likelihood or Bayesian framework to infer rates and direction of historical migration events (Beerli and Felsenstein 1999, 2001) and allows for asymmetrical migration. We ran extensive testing runs with Migrate- $\mathrm{N}$ to test various search parameters, prior distributions, chain lengths, and replicates. We inferred a migration matrix among 11 of our putative populations (all populations with $N \geq 7$; table 1 ). We used the Bayesian implementation of Migrate- $\mathrm{N}$ and the following parameters: wide uniform priors on $\theta$ ( 0.0 minimum and 0.1 maximum $)$ and migration $(M$, mutation-scaled migration; 0.0 minimum and $5 \times 10^{4}$ maximum); slice sampling proposal distributions for both genealogies and demographic parameters; a single long cold chain with $2 \times 10^{6}$ steps burn-in, and nine heated chains; $5 \times 10^{4}$ recorded steps, sampling every 100 steps, for a total of $5 \times 10^{6}$ post-burn-in visited states (per locus). We assessed whether individual locus MCMC chains had reached a stationary distribution by visualizing the parameter values in the program Tracer (Rambaut and Drummond 2007) and in R (R Development Core Team 2008). We calculated the migrants per generation ( $4 \mathrm{~nm})$ by multiplying the mean $M$ by the recipient population's estimated mean $\theta$ value for a given population pair.

Assessing Asymmetrical Migration. To determine whether net gene flow was asymmetrically biased from the range center to the range margin (from south to north), we conducted permutation tests in $\mathrm{R}$ ( $\mathrm{R}$ Development Core Team 2008). We calculated the mean difference in migration for each population pair and then permuted the migration estimates $\left(1 \times 10^{5}\right.$ times $)$ to build a null distribution of expected differences in migration rates between population pairs. This expected distribution was used to assess significance of our observed estimates. Migration values are percentage of migrant ancestry (contemporary 
rates, BayesAss) or migrants per generation ( $4 \mathrm{~nm}$, historical rates, Migrate-N) from population $x$ to population $y$, and vice versa.

\section{Phenotypic Data}

Plant Propagation. In April 2009, field-collected seeds from seven to 26 maternal plants per population were planted in 3-inch pots containing Fafard Super-Fine Germinating Mix (Conrad Fafard, Agawam, MA) in greenhouses at Colorado State University. Greenhouse temperatures averaged $24^{\circ} / 20^{\circ} \mathrm{C}$ during the day/night, with a 16L : 8D photoperiod. In September 2009, plants were transferred to 1-gallon pots and apical meristems were pruned to encourage branching. In November 2009, when plants had grown sufficiently large to allow for cuttings to be taken weekly, we selected seven to 10 of the largest, healthiest plants per population for assessment of growth responses to temperature. We estimated genotypic growth response curves by creating up to 28 vegetative clones of each genotype. Up to four clones per genotype were placed for 1 week in each of seven different temperature regimes $\left(15^{\circ} / 0^{\circ}, 20^{\circ} / 5^{\circ}, 25^{\circ} / 10^{\circ}, 30^{\circ} / 15^{\circ}, 35^{\circ} / 20^{\circ}, 40^{\circ} / 25^{\circ}\right.$, and $45^{\circ} \%$ $30^{\circ} \mathrm{C}$ ), each replicated twice in two identical growth chambers (Percival LT-105, Percival, Perry, IA). Up to two cuttings per plant were made each week beginning in November, resulting in a series of sequential growth chamber runs that ended in April 2010. In total, we made 2,432 clones. For additional details on cloning methods and growth chamber conditions, see Angert et al. (2011).

Temperature Response Curves. The following size measurements were taken on each clone before and after exposure to the growth chamber temperature regime: length of primary stem, number of secondary stems, length of an average secondary stem, number of rhizome sprouts, and length of an average rhizome sprout. From these measurements we estimated total stem length at each time point as the sum of primary, secondary, and rhizome lengths. We then calculated relative growth rate (RGR) as the change in total stem length per initial total stem length per day. Before conducting statistical analyses, we examined the effect of rooting status on RGR. Because RGR was often negative for unrooted cuttings, we excluded these individuals from analysis $(N=429)$.

Following Angilletta et al. (2006), we compared the fit of several candidate functions that could describe relative growth rate as a function of temperature, including several that would permit asymmetrical skew. For all populations, the symmetrical Gaussian function had the lowest Akaike Information Criterion (AIC) value (Angert et al. 2011) and is the basis of all subsequent analyses reported here. Analyses were conducted using the nls function in R. We used genotypic means (mean RGR across clones of each genotype at each temperature) rather than individual clones as data lines to avoid pseudoreplication. We defined the temperature optimum of relative growth rate (RGR $T_{\text {opt }}$ ) as the temperature where the first derivative of the Gaussian function equaled 0 . Note that RGR $T_{\text {opt }}$ is our metric for the phenotype realized by each population; it is not necessarily equivalent to the adaptive optimum for that location. To test for a phenotypic cline, we regressed RGR $T_{\text {opt }}$ versus latitude. We permuted data lines among populations randomly without replacement, maintaining observed sample sizes per temperature and population, to determine the likelihood of obtaining a phenotypic cline of at least the same magnitude as the observed cline.

\section{Climate Data}

Climate data were extracted for each collection locality (table 1) using the ClimateWNA program, which uses digital elevation models to downscale monthly data at $2.5 \times 2.5$ arcmin resolution from PRISM (Daly 2006) for the period 1961-1990 (described in detail in Wang et al. 2006). Although many calculated and derived climatic parameters are available, we focus here on one that we selected a priori for relating to temperature response curves: maximum temperature during the peak month of the growing season, July (July $T_{\max }$ ). We chose to use a maximum temperature because we modeled the growth chamber temperature regimes by their maximum temperatures (e.g., the RGR data from the $40^{\circ} / 25^{\circ} \mathrm{C}$ regime were fit to a temperature of $40^{\circ} \mathrm{C}$ ). However, because climatic parameters were highly correlated, other temperature metricssuch as average temperatures and temperatures from different months-yielded qualitatively similar patterns. To test our second prediction that phenotypic clines are shallower than environmental gradients, we performed an ANCOVA using the $\mathrm{lm}$ function in $\mathrm{R}$ ( $\mathrm{R}$ Development Core Team 2008). We tested for a significant difference in the slope of temperature versus latitude between the phenotypic and environmental data sets. We compared support for the full four-parameter model (two slopes and two intercepts) to all possible reduced models, using the AIC.

\section{Integration of Genetic, Phenotypic, and Climate Data}

To integrate phenotypic and climatic data with the genetic data and test whether swamping gene flow pushes population phenotypes away from local temperature optima, our approach was to relate the temperature response phenotype of each population to the magnitude and source of gene flow from populations occupying different climatic regimes. As an estimate of the potential mismatch between 
Table 2: AMOVA results

\begin{tabular}{|c|c|c|c|c|}
\hline Sources of variation & $\mathrm{df}$ & $\begin{array}{l}\text { Sum of } \\
\text { squares }\end{array}$ & $\begin{array}{c}\text { Variance } \\
\text { components }\end{array}$ & $\begin{array}{c}\text { Variation } \\
(\%)\end{array}$ \\
\hline Among groups & 1 & 15.45 & .04 & 2.19 \\
\hline Among populations within groups & 11 & 104.86 & .47 & 23.54 \\
\hline Within populations & 215 & 317.91 & 1.48 & 74.28 \\
\hline Total & 227 & 438.22 & 1.99 & \\
\hline
\end{tabular}

phenotype and environment, we defined phenotypic deviation as the difference between RGR $T_{\text {opt }}$ and July $T_{\max }$. This metric assumes that environmental temperature is a reasonable proxy for the adaptive optimum for that location because selection on temperature response phenotypes is correlated with environmental temperature, an assumption that is supported by prior physiological ecology (Decker 1958; Hiesey et al. 1971; Angert 2006) and experimental evolution (Angert et al. 2008) in this system. We calculated two estimates of weighted immigration, latitude-weighted immigration (LWI) and temperatureweighted immigration (TWI). For each donor-recipient population pair, we multiplied the immigration estimate from donor to recipient by the difference in latitude (LWI) or July maximum temperature (TWI) between the two populations. A net immigration value for each recipient population was then calculated as the sum of all distanceor temperature-weighted immigration estimates from all possible donors (e.g., $\mathrm{LWI}_{j}=\sum^{i} \mathrm{LWI}_{i \rightarrow j}$ ). LWI is positive when net immigration into a focal population is from the north and negative when net immigration is from the south; an LWI of zero would indicate that immigration from the north exactly balances that from the south. Because we calculated TWI also as donor minus recipient habitat temperatures, the directionality of TWI is inverse to that of LWI: TWI is positive when net immigration is from hotter localities and negative when net immigration is from cooler localities. Because our data collection points fall along a latitudinal transect, there is an opportunity for bias in the LWI and TWI metrics. For example, the third most southern population (Tuolumne) can potentially receive migrants from nine populations to its north but only two populations to its south, so even random data will likely produce a net influx of migrants from the north. To account for this bias, we developed standardized metrics for LWI and TWI $\left(\mathrm{LWI}_{\mathrm{std}}, \mathrm{TWI}_{\mathrm{std}}\right)$ using permutations to make null distributions of expected LWI and TWI values $\left(\mathrm{LWI}_{\text {exp }}, \mathrm{TWI}_{\text {exp }}\right)$. We permuted the migration estimates among populations $\left(\mathrm{LWI}_{\mathrm{obs}}, \mathrm{TWI}_{\mathrm{obs}}\right.$ ), randomly shuffling the relationship between latitude and the migration matrix. For each population, we calculated the standardized LWI as $\mathrm{LWI}_{\text {std }}=\left(\mathrm{LWI}_{\mathrm{obs}}-\mathrm{LWI}_{\text {exp }}\right) / \operatorname{stdev}\left(\mathrm{LWI}_{\text {exp }}\right)$; the same equation was used for standardized TWI, replacing LWI with TWI observed and expected values. This approach was inspired by phylogenetic structure metrics that account for species richness (Webb 2000). These standardized metrics correct for bias in our sampling design while making the weighted metrics comparable among populations; these are the values we report in our results. For comparison of recent versus long-term effects of gene flow, we calculated LWI and TWI using gene flow estimates from BayesAss and Migrate- $\mathrm{N}$ and related both types of estimates to PD.

\section{Results}

\section{Genetic Structure and Polymorphism across the Geographic Range}

We found significant population genetic structure based on haplotype frequencies (AMOVA: $\Phi_{\mathrm{ST}}=0.74, P<$ .0001 ), but we found no evidence of genetic differentiation between center and edge population groups (betweengroup variation $=2.19 \%, P=.11$; table 2 ). Genetic differentiation between particular population pairs was on the whole quite strong (e.g., mean $F_{\mathrm{ST}}=0.25, \mathrm{SD}=$ 0.11 ; table C1), leading to significant IBD $(Z=-118.62$, $r=0.24, P=.03$ ).

We found no significant relationships between latitude and any of the molecular diversity metrics (segregating sites $S, R^{2}=0.33, P=.20$ [quadratic]; nucleotide diversity $\pi, R^{2}=0.35, P=.17$ [quadratic]; haplotype richness, $R^{2}=0.24, \quad P=.34 \quad$ [quadratic]; private haplotypes, $R^{2}=0.25, P=.12$ [linear]; table 3). Mutation-scaled population genetic diversity $(\theta)$, as estimated by Migrate$\mathrm{N}$, also did not vary with latitude $\left(R^{2}=0.22, P=.16\right.$; table 3). The median $\theta$ estimate for one population, Kaweah, was two orders of magnitude higher than all other estimates. Unlike all other populations, the posterior distribution for Kaweah was not a unimodal curve (truncated at 0 ) and hence did not have a clear central tendency. As such, we excluded the $\theta$ estimate for Kaweah (and associated migration into this population) from subsequent historical migration analyses (see "Discussion"). 


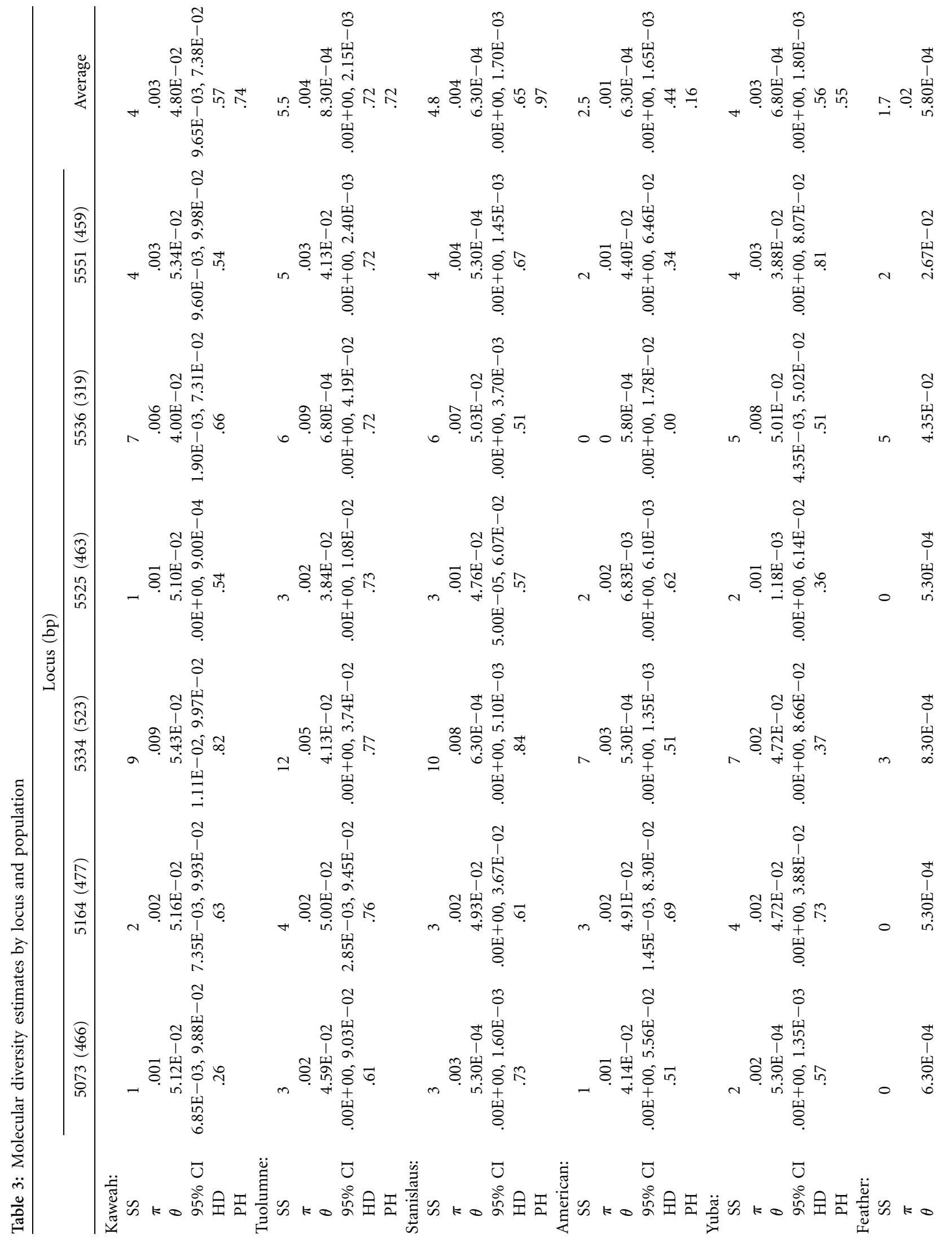




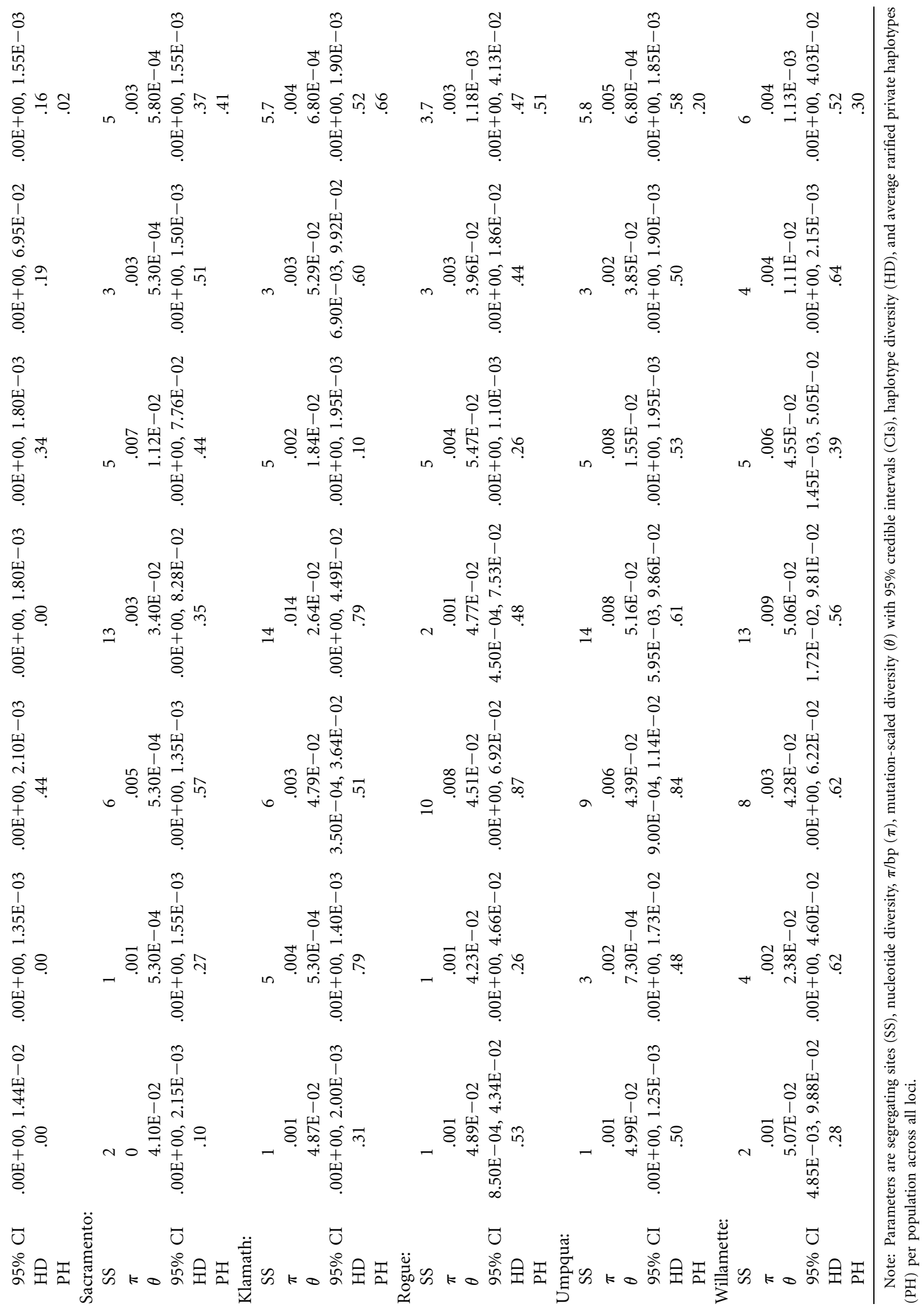




\section{Contemporary and Historical Migration Rates}

On the basis of contemporary estimates of gene flow, most population pairs shared relatively few migrants $(<2 \%)$, but some populations contributed as much as $22 \%$ to other populations (e.g., American migration into Tuolumne; table C2). Net gene flow was not asymmetrically biased (mean migration north $=0.017$, migration south $=$ $0.021, P=.54)$. Historical migration rates were moderate among populations ( $4 \mathrm{~nm}$ ranging from $\sim 10$ to 38 ) and had a significantly asymmetric bias to the north (mean migration north $=22.29$, migration south $=19.34$, $P=.01 ;$ table $\mathrm{C} 3)$.

\section{Temperature Response Curves}

Temperature response curves had a characteristic unimodal shape with a single temperature optimum for relative growth rate $\left(\mathrm{RGR} \mathrm{T}_{\mathrm{opt}}\right.$; fig. D1). Although standard errors around the estimates of RGR $\mathrm{T}_{\mathrm{opt}}$ were relatively high, resulting in confidence intervals for $R G R T_{\text {opt }}$ that were broadly overlapping, $\mathrm{RGR} \mathrm{T}_{\text {opt }}$ significantly declined with increasing latitude $\left(b=-0.31, R^{2}=0.74, P=\right.$ .0003 ; fig. 3, open circles). Only nine of 10,000 random permutations had a more negative slope, indicating that the inferred cline is highly unlikely to have arisen by chance despite high sampling error that made pairwise differences between populations undetectable. July $T_{\max }$ decreased rapidly with increasing latitude but with considerable scatter $\left(b=-0.90, R^{2}=0.41, P=.03\right.$; fig. 3 , solid circles). RGR $T_{\text {opt }}$ was only marginally related to July $T_{\max }\left(b=0.13, R^{2}=0.26, P=.09\right)$. ANCOVA suggested that July $T_{\max }$ declined more rapidly with increasing latitude than did RGR $T_{\text {opt }}$ (table E1).

\section{Phenotypic Deviation and Latitude-and Temperature- Weighted Immigration Clines}

For both contemporary and historical gene flow estimates, there was no significant relationship between standardized latitude-weighted immigration $\left(\mathrm{LWI}_{\text {std }}\right)$ and latitude (contemporary, $R^{2}=0.18, P=.22$; historical, $R^{2}=0.003$, $P=.90$; fig. $4 A, 4 B$ ). In contrast, contemporary standardized temperature-weighted immigration $\left(\mathrm{TWI}_{\text {std }}\right.$ ) varied significantly with latitude; southern populations received more migrants from populations from cooler environments, while northern populations received more migrants from populations from hotter environments $\left(R^{2}=0.46, P=.03\right.$; fig. $\left.4 C\right)$. Historical TWI $\mathrm{Ttd}_{\text {std }}$ did not vary with latitude $\left(R^{2}=0.13, P=.33\right.$; fig. $\left.4 D\right)$.

Phenotypic deviation (PD) did not vary significantly with latitude $\left(R^{2}=0.22, P=.18\right.$; fig. $\left.5 A\right)$. The influx of contemporary latitude-weighted migrants $\left(\mathrm{LWI}_{\text {std }}\right)$ signif-

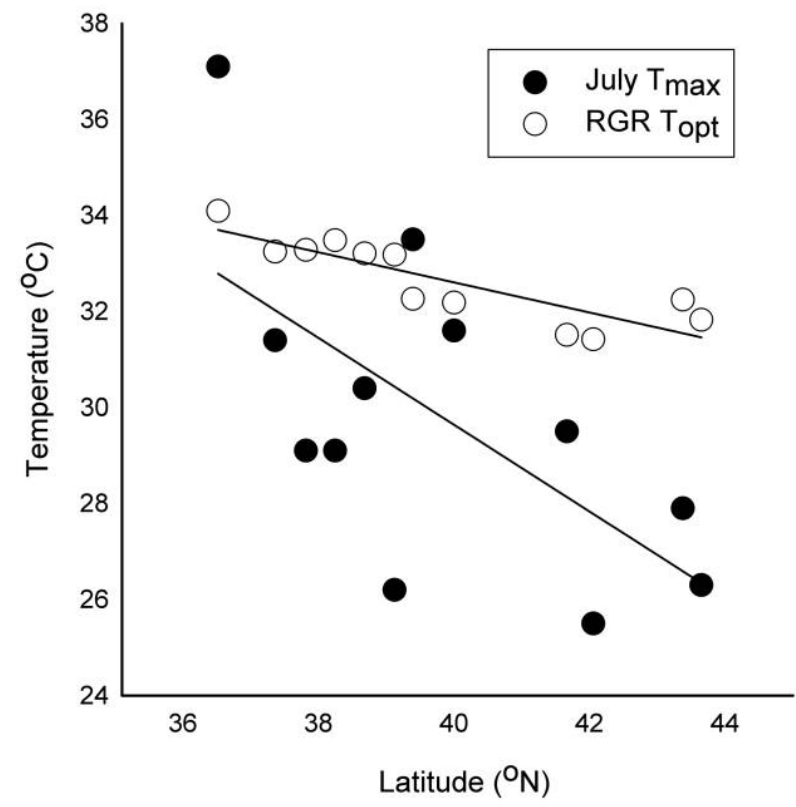

Figure 3: Support for prediction that relative growth rate (RGR) $T_{\text {opt }}$ decreases more slowly with latitude than does July $T_{\max }$. Full ANCOVA model yields a marginally significant shallower slope for RGR $T_{\text {opt }}$ against latitude than for July $T_{\max }$ (RGR $T_{\text {opt }}$ slope $=-0.31$, July $T_{\max }$ slope $=-0.90, P=.11$; table $\mathrm{F} 1$ [app. A-F are available in a zip file in the online edition of the American Naturalist]). Reduced ANCOVA model assuming a common intercept yields a significantly shallower slope for RGR $T_{\text {opt }}$ against latitude than for July $T_{\max }$ (RGR $T_{\text {opt }}$ slope $=-0.57$, July $T_{\max }$ slope $=-0.65, P=$ .002 ; table E1). Other possible reduced models had substantially higher AIC values and are not presented here (but see table E1).

icantly explained $\mathrm{PD}$ across populations $\left(R^{2}=0.53\right.$, $P=.02$; fig. $5 B)$, but the influx of historical migrants did not $\left(R^{2}=0.18, P=.26\right.$; fig. $\left.5 C\right)$. In the contemporary case, in populations where PD was positive (cooler RGR $\mathrm{T}_{\text {opt }}$ than the local environment), the net influx of latitudeweighted migrants came from the north, while in populations where $P D$ was negative (hotter RGR $T_{\text {opt }}$ than the local environment), the net influx of migrants came from the south. In contrast, $\mathrm{TWI}_{\text {std }}$, both contemporary and historical, did not significantly explain PD across populations (contemporary, $R^{2}=0.03, P=.61$; historical, $R^{2}=0.03, P=.67$; fig. $\left.5 D, 5 E\right)$.

\section{Discussion}

We illustrated a new approach for quantifying the effects of swamping gene flow on phenotypes that relates the degree of phenotypic-environment mismatch exhibited by a given population to the amount of environmentally weighted gene flow received by that population. This ap- 
Contemporary Gene Flow

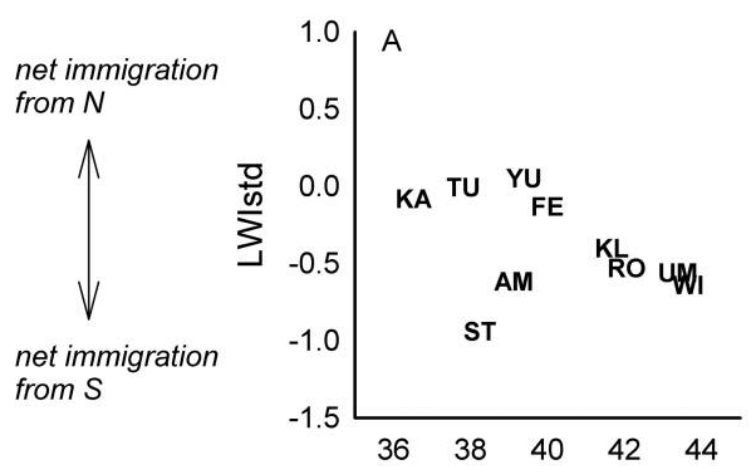

net immigration

from hotter

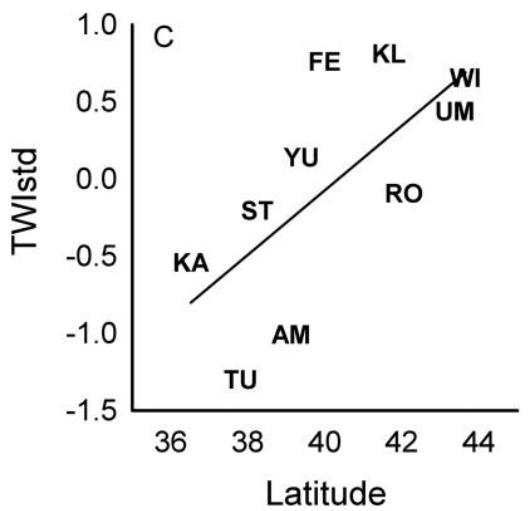

Historical Gene Flow
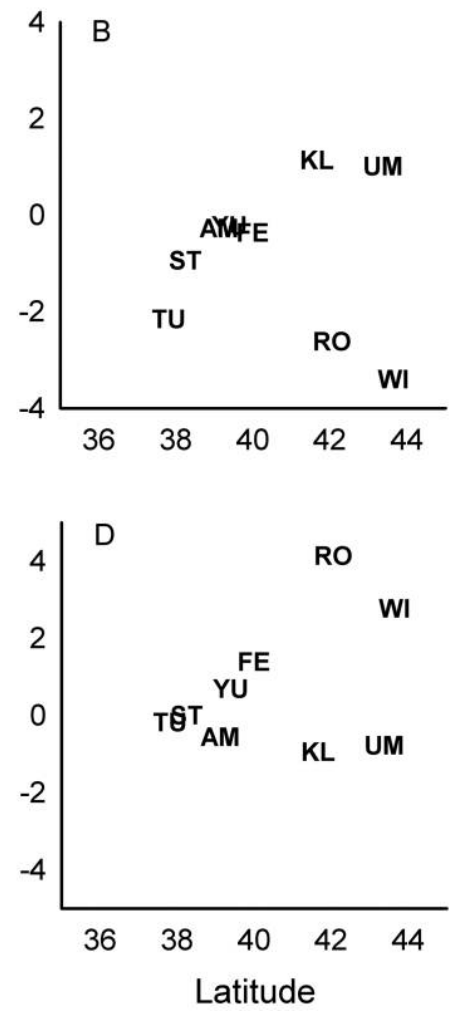

Figure 4: Relationship of standardized latitude-weighted immigration ( $\mathrm{LWI}_{\text {std; }}$; top row) and standardized temperature-weighted immigration $\left(\mathrm{TWI}_{\text {std }}\right.$; bottom row) versus latitude. Immigration estimates in left column are contemporary rates based on Bayesian assignment, and estimates in right column are historical rates based on coalescent inference. Values of $\mathrm{LWI}_{\text {std }}>0$ indicate net migration from the north, and values of $\mathrm{LWI}_{\text {std }}<0$ indicate net migration from the south; values of $\mathrm{TWI}_{\text {std }}>0$ indicate net migration from populations with warmer environments, and values of $\mathrm{TWI}_{\text {std }}<0$ indicate net migration from populations with cooler environments, on the basis of July maximum temperature.

proach is a flexible and tractable way to estimate how gene flow may be influencing phenotypes in populations arrayed on an environmental gradient. By weighting migration by the latitudinal distance or temperature "distance" from which migrants arrived, our method takes into account the greater potential for maladaptive genotypes to be introduced to a given population, assuming that the farther away a donor population is (in terms of spatial distance or temperature difference), the more likely it is that these populations include maladaptive alleles that would be unfit in the recipient population. This approach could be applied to any system in which field estimates of gene flow can be inferred, relevant environmental parameters estimates are available, and the study organism can be grown under controlled conditions to evaluate phenotypic responses to variation in the environmental variable of interest. This approach requires that environmental variables relevant to fitness be used to weight the distance of migrants and that reasonable estimates of gene flow can be inferred.

\section{Gene Flow and Phenotype-Environment Mismatch in Mimulus cardinalis}

In the plant species Mimulus cardinalis, we found evidence of historical asymmetrical gene flow from central (southern) to marginal (northern) populations, supporting one of the predictions of the swamping gene flow hypothesis. Net contemporary gene flow was not statistically asymmetrical, but contemporary temperature-weighted immigration $\left(\mathrm{TWI}_{\text {std }}\right)$ varied significantly with latitude, whereby northern marginal populations received a net influx of migrants from hotter environments. We also found that the regional term in an AMOVA explained very little of the overall genetic variance across the range, suggesting that while genetic differentiation was moderately large 

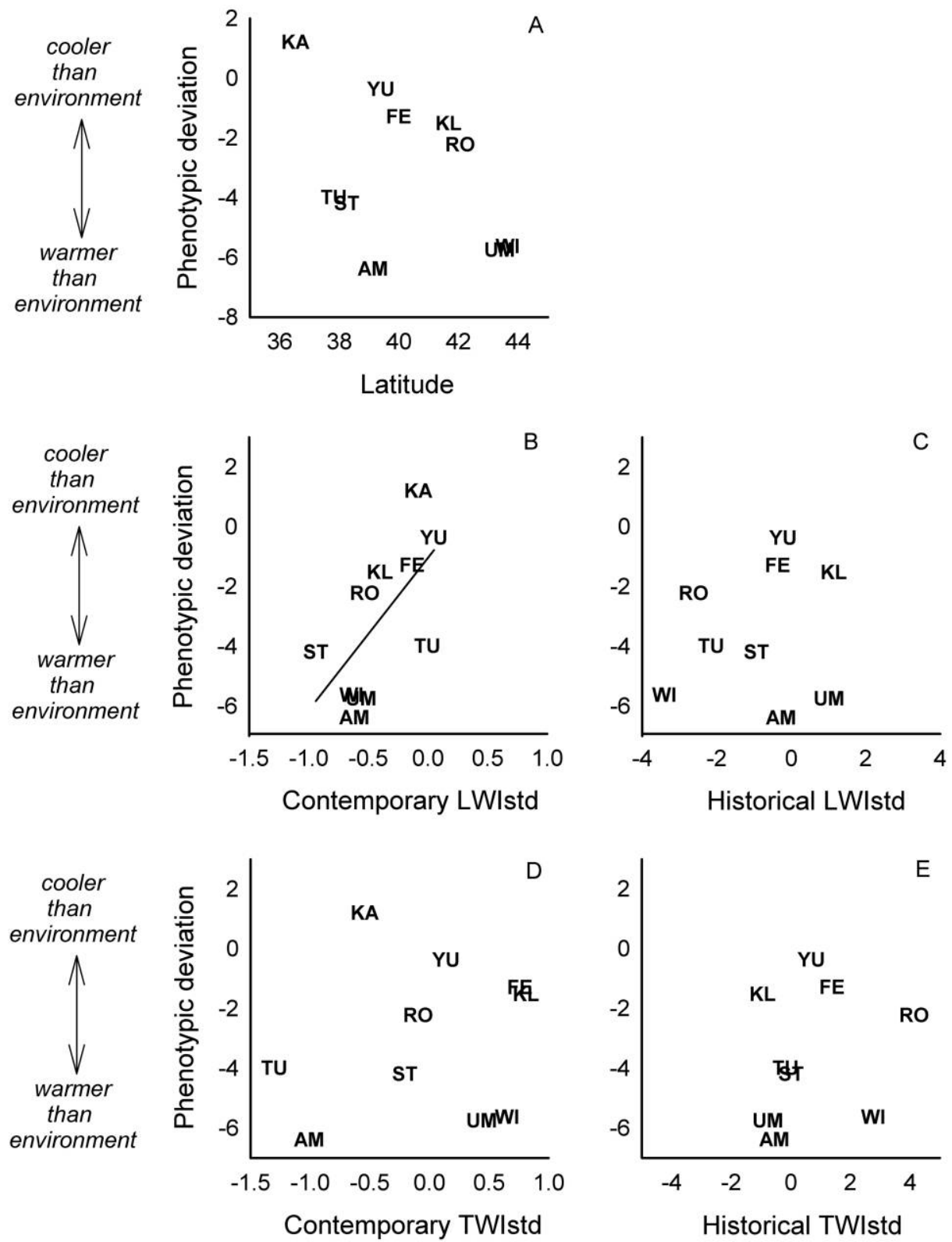

Figure 5: Relationship of phenotypic deviation (PD) and latitude $(A)$, standardized latitude-weighted immigration $\left(\mathrm{LWI}_{\mathrm{std}}\right)$ based on contemporary migration rates $(B), \mathrm{LWI}_{\text {std }}$ based on historical migration rates $(C)$, standardized temperature-weighted immigration $\left(\mathrm{TWI}_{\mathrm{std}}\right)$ based on contemporary migration rates $(D)$, and $\mathrm{TWI}_{\mathrm{std}}$ based historical migration rates $(E)$. Values of $\mathrm{PD}>0$ indicate that the relative growth rate (RGR) temperature response optimum is cooler than the local environment, while values of $P D<0$ indicate that the RGR temperature response optimum is warmer than the local environment.

overall, gene flow could be keeping marginal and central populations from becoming genetically distinct. Despite these three lines of evidence, we did not find that marginal populations were the ones that exhibited the greatest potential for maladaptation to temperature extremes at their site, as measured by phenotypic deviation.

We also found evidence that was not consistent with the swamping gene flow framework. First, the average population genetic differentiation across the range was rather large, suggesting that the total level of gene flow should be small. Supporting this notion, the majority of contemporary pairwise gene flow estimates were typically low. For contemporary estimates, most populations owe $<1 \%$ of their genotypes to recent migrants (within the last two 
generations). In contrast, our historical estimates of gene flow suggest that most population pairs share on the order of five migrants per generation (e.g., 4nm means 20). These large numbers could indicate that ancestral polymorphism is upwardly biasing our historical migration estimates. However, such a pattern could potentially be explained by the annual migration of hummingbirds, the principle pollinators of $M$. cardinalis. During migration, hummingbirds travel long distances each night and feed voraciously during the day (Phillips 1975), providing opportunity for the hummingbird migration to impact the net flux of long-distance gene flow among $M$. cardinalis populations. Second, we did not find a reduction in haplotype richness, nucleotide diversity, number of private haplotypes, or mutation-scaled diversity $(\theta)$ with latitude as predicted based on the assumption that swamping gene flow would introduce a randomly sampled subset of genetic diversity to northern populations. Finding no reduction in genetic diversity in marginal populations contrasts markedly with the results of Moeller et al. (2011), who found significantly reduced genetic diversity in marginal populations of Clarkia xantiana. Finally, while we did find that populations receiving the greatest influx of distant migrants (high $\mathrm{LWI}_{\text {std }}$ ) had temperature response phenotypes that are farther from the local temperature (high PD), there was no trend between PD and latitude. Clinal variation in temperature response phenotype was shallower than the environmental gradient in growing season temperature, suggesting that gene flow may indeed homogenize phenotypes among populations. Taken together, these lines of evidence indicate that while gene flow may be important in constraining the ability of some populations to track optimal conditions, these populations are not necessarily located only at the range margin.

\section{Assumptions, Caveats, and Additional Approaches}

This study has several strengths and weaknesses that should be considered when interpreting these results. Our phenotypic data focus on one key variable, relative growth rate in response to temperature, but certainly other dimensions of the multivariate phenotype are relevant to understanding fitness across the geographic range. Given previous work that has implicated temperature as a potentially important variable limiting growth and reproduction in M. cardinalis (Angert 2006; Angert et al. 2008), this phenotype is a reasonable and relevant starting point for investigating PD across the range. Estimates of temperature optima for growth might be improved by using inbred lines as genotypic replicates rather than vegetative clones. We also made the assumption that July maximum temperature was equivalent to the selective optimum within each local environment. We were unable to account for microhabitat differences among populations that may mediate selection on temperature response phenotypes. Likewise, variation in the phenology of local populations could alter the selective regimes that different populations may actually experience. However, preliminary examination of variation in phenology with latitude, based on the reproductive status of herbarium collections as well as flowering times in a greenhouse common garden, did not reveal a strong relationship (A. L. Angert, unpublished data), suggesting that phenological differences among populations across the transect may not be particularly strong.

We used only a small subset of loci from the M. cardinalis genome to draw conclusions about the species as a whole. Given recent advances in data collection and analysis in the age of population genomics (Pool et al. 2010), a larger genetic data set would be an important way to make more robust conclusions about migration, population differentiation, and genetic diversity. Still, the methods we employed to estimate migration rates from genetic data have been shown to be robust in simulation studies (e.g., Beerli 2004; although this simulation study was based on a scenario with few populations and many loci, the opposite of the situation presented here), and both the Bayesian clustering method and the coalescent genealogical sampler we used have the great advantage of being flexible tools that can infer asymmetrical rates of gene flow, compared with traditional $F_{\mathrm{ST}}$-based metrics that force the assumption of rate symmetry between population pairs. For the historical migration estimates, we were attempting to infer a large number of parameters (126) with six loci, likely pushing the limits of Migrate$\mathrm{N}$. However, the majority of our migration estimates had unimodal posterior distributions (but with wide credible intervals), suggesting that the MCMC sampling of migration parameters had reached a stable distribution. However, estimates of $\theta$ for one population, Kaweah, consistently showed fairly flat posteriors with no indication of a central tendency. This result suggests that Kaweah's $\theta$ estimate was unreliable, and hence we excluded migration rates into Kaweah for our asymmetry and PD analyses (since $4 \mathrm{~nm}=$ mutation-scaled migration rate $M$ multiplied by the receipt population's $\theta$ ). Interestingly, Kaweah is close to our estimate of the geographic range center yet also represents the southern sampling boundary of our latitudinal transect. There is a possibility that gene flow from more southern, unsampled populations could be influencing the poor $\theta$ estimates in Kaweah. Unsampled populations could have detrimental effects on parameter estimates because Migrate- $\mathrm{N}$ assumes that all populations exchanging migrants are sampled (Beerli 2004). Clearly, such an assumption is difficult to meet for almost any empirical study, yet this method has been widely used to infer migration rates in natural populations. 
Future work on how gene flow and phenotypic divergence impact the geographic range limits could take a number of directions. First, an inherent assumption of this study of scarlet monkeyflowers is that phenotypic responses to varying temperature regimes are under natural selection, a conjecture supported by prior physiological ecology (Decker 1958; Hiesey et al. 1971; Angert 2006) and experimental evolution (Angert et al. 2008). Measuring the strength and direction of assumed selection pressures across populations will provide insight into the magnitudes of gene flow and environmental distance that are necessary to push local populations away from phenotypic optima. Estimates of fitness in natural populations will also aid interpretation of the potential maladaptive effects of gene flow (e.g., Anderson and Geber 2010). Second, including additional relevant phenotypic characters and environmental variables in analyses such as those conducted here may help elucidate how gene flow and phenotypic divergence are related across the geographic range and provide insight into the degree of correlation among different phenotypic characters that are simultaneously under divergent selection pressures in central and marginal populations. Third, experimental manipulation of gene flow-implemented by crossing marginal populations with pollen donors from various populations that differ in their magnitude of differences in latitude, temperature, or other relevant variables-would provide a powerful test of the swamping gene flow hypothesis (Sexton et al. 2009; Moeller et al. 2011). Offspring of these crosses could be either reared in growth chamber conditions that mirror marginal environmental profiles or transplanted directly into the field to assess how gene flow impacts fitness. Finally, the inability of swamping gene flow to adequately explain the northern geographic range limit in M. cardinalis in this study suggests that other hypotheses may be more plausible.

\section{Consideration of Equilibrial and Nonequilibrial Geographic Range Limits}

This study, like most investigations of range limits, begins with the underlying assumption that the edges of geographic ranges are concordant with niche limits. In other words, the edge of a species' geographic range is assumed to represent a stable limit because conditions beyond the limit are unsuitable for the phenotype of a given species. This framework contrasts with a different approach to understanding species distributions that has been taken by researchers in the broad field of phylogeography (Avise 2000). Much phylogeography, particularly in northern temperate regions, has focused on understanding geographic range expansions and contractions, often linking these dynamics with glacial cycles or other major climate events (e.g., Petit et al. 2002). Hence, phylogeographers often assume that range edges are nonequilibrial boundaries and work to infer the direction and timing of the expansion or contraction of species' ranges, while evolutionary ecologists assume that the range edges are equilibrial boundaries, held in place through a balance of processes, such as selection and gene flow. Distinguishing between these contrasting hypotheses represents a fundamental challenge to the investigation of range limits. Since we cannot observe how processes in the past have shaped the current distribution of species, we must rely on inferences from indirect methods, such as analyzing the distribution and diversity of genetic polymorphisms. Despite the potential power of genetic data to elucidate past demographic events, similarities in both the underlying processes and the genetic outcomes of nonequilibrial events such as range expansions and equilibrial processes such as swamping gene flow make interpretations based solely on genetic data difficult. For example, a recent range expansion can leave genetic signatures that are very similar to the expectations derived from the swamping gene flow hypothesis, both of which can predict lower genetic diversity and increased genetic differentiation along range margins. Inference of historical demographic parameters, such as population growth rates and migration rates, might provide an additional line of evidence to help distinguish range limit hypotheses. Data from multiple loci (tens to hundreds) will provide more robust estimates of demographic history (Carling and Brumfield 2007). Despite the potential usefulness of historical demographic inferences for an evolutionary ecology perspective on range limits, using a coalescent framework has been largely absent from range limit studies, although this work has begun (e.g., Moeller et al. 2011).

In this study, we made an effort to elucidate the potential influence of historical events on $M$. cardinalis range limits by inferring both contemporary and historical rates of gene flow. If a recent historical event, such as a postglacial range expansion, has played an important role in shaping the current northern range margin in $M$. cardinalis, we may expect discordant patterns between contemporary and historical gene flow. We found that historical gene flow was asymmetrical from south to north, which could be interpreted as evidence of a range expansion out of $M$. cardinalis's putative ancestral range center in the southern Sierra Nevada (Beardsley et al. 2003). However, we did not detect lowered genetic diversity among northern marginal populations, as would be expected under such a scenario. In contrast, contemporary gene flow was greatest out of the northern reaches of the Sierra Nevada Range, near the northern edge of the range center, as we defined it. Interestingly, field surveys of population frequency across the range do indicate that the highest concentration 
of populations is found in the north-central Sierra Nevada Mountains, close to the epicenter of the estimated contemporary migration output (A. L. Angert and J. R. Paul, unpublished data). Taken together, these results suggest that the patterns of gene flow over evolutionary time and in recent history may not be entirely concordant. It is interesting that contemporary immigration explained phenotypic mismatch yet historical immigration did not. In this system at least, relatively recent gene flow estimates may be most pertinent to investigations of swamping gen flow and understanding the impact of gene flow on phenotypes.

\section{Conclusions and Synthesis}

The swamping gene flow hypothesis of range limits has received considerable theoretical consideration, but em pirical support is scarce (Bridle et al. 2009; Moeller et al. 2011). Our study system-populations of the perennial herb $M$. cardinalis distributed along a latitudinal gradient-meets the key assumptions of the swamping gene flow hypothesis (environmental gradient, phenotypic cline, asymmetrical gene flow), making this an appropriate system to test this hypothesis. We developed a novel approach for using the relationship between phenotypeenvironment mismatch and the degree of potentially maladaptive gene flow to elucidate the impact of swamping gene flow in natural populations. We found evidence supporting the underlying mechanism of this hypothesis, mal. adaptive gene flow creating phenotypic mismatch to local conditions. However, phenotypic mismatch did not increase from the center to the range margin in this study, indicating that while maladaptive gene flow could hinder local adaptation in this species, it does not appear to explain its northern geographic range limit. Our general approach can be easily applied to other natural systems where the impact of gene flow on local adaptation is of interest.

\section{Acknowledgments}

We thank M. A. Geber for inviting us to participate in this symposium. We thank R. Chong, M. DeMarche, J_ McKay, and P. Reeves for helpful feedback and discussions. We thank H. Bender, T. Green, B. Jones, A. Koch, C. Nichols, A. Robinson, and M. Weibush for help in the molecular lab, greenhouse, and growth chambers, and J. Matsuura and L. Mouttet for greenhouse support. T. Bradshaw generously supplied primers for molecular markers. We thank M. A. Geber, D. Moeller, and two anonymous reviewers for comments that improved thi: article. Thanks to the National Forest Service, the National Park Service, and California State Parks for permission to collect in the field. Colorado State University and the National Science Foundation (DEB-0950171) funded this work.

\section{Literature Cited}

Alexander, P. J., G. Rajanikanth, C. D. Bacon, and C. D. Bailey. 2007. Recovery of plant DNA using a reciprocating saw and silica-based columns. Molecular Ecology Notes 7:5-9.

Alleaume-Benharira, M., I. R. Pen, and O. Ronce. 2006. Geographical patterns of adaptation within a species' range: interactions between drift and gene flow. Journal of Evolutionary Biology 19:203-215.

$\rightarrow$ Anderson, J. T., and M. A. Geber. 2010. Demographic source-sink dynamics restrict local adaptation in Elliott's blueberry (Vaccinium elliottii). Evolution 64:370-384.

$\rightarrow$ Angert, A. L. 2006. Growth and leaf physiology of monkeyflowers with different altitude ranges. Oecologia (Berlin) 148:183-194.

Angert, A. L., and D. W. Schemske. 2005. The evolution of species' distributions: reciprocal transplants across the elevation ranges of Mimulus cardinalis and M. lewisii. Evolution 59:222-235.

$\rightarrow$ Angert, A. L., H. D. Bradshaw, D. W. Schemske, and J. Kohn. 2008. Using experimental evolution to investigate geographic range limits in monkeyflowers. Evolution 62:2660-2675.

Angert, A. L., S. N. Sheth, and J. R. Paul. 2011. Incorporating population variation in thermal performance into geographic range shift predictions. Integrative and Comparative Biology, doi: 10.1093/icb/icr048.

Angilletta, M. J., A. F. Bennett, H. Guderley, C. A. Navas, F. Seebacher, and R. S. Wilson. 2006. Coadaptation: a unifying principle in evolutionary thermal biology. Physiological and Biochemical Zoology 79:249-268.

Antonovics, J. 1976. The nature of limits to natural selection. Annals of the Missouri Botanical Garden 63:224-247.

Avise, J. C. 2000. Phylogeography: the history and formation of species. Harvard University Press, Cambridge, MA.

Barton, N. 2001. Adaptation at the edge of a species' range. Pages 365-392 in J. Silvertown, ed. Integrating ecology and evolution in a spatial context. Blackwell, London.

$\rightarrow$ Beardsley, P. M., A. Yen, and R. G. Olmstead. 2003. AFLP phylogeny of Mimulus section Erythranthe and the evolution of hummingbird pollination. Evolution 57:1397-1410.

$\rightarrow$ Beerli, P. 2004. Effect of unsampled populations on the estimation of population sizes and migration rates between sampled populations. Molecular Ecology 13:827-836.

Beerli, P., and J. Felsenstein. 1999. Maximum-likelihood estimation of migration rates and effective population numbers in two populations using a coalescent approach. Genetics 152:763-773.

. 2001. Maximum likelihood estimation of a migration matrix and effective population sizes in $n$ subpopulations by using a coalescent approach. Proceedings of the National Academy of Sciences of the USA 98:4563-4568.

$\rightarrow$ Blows, M. W., and A. A. Hoffman. 2005. A reassessment of genetic limits to evolutionary change. Ecology 86:1371-1384.

$\rightarrow$ Bradshaw, A. D. 1991. The Croonian lecture, 1991: genostasis and the limits to evolution. Philosophical Transactions of the Royal Society B: Biological Sciences 333:289-305.

Bridle, J. R., and T. H. Vines. 2007. Limits to evolution at range margins: when and why does adaptation fail? Trends in Ecology \& Evolution 22:140-147. 
$\rightarrow$ Bridle, J. R., S. Gavaz, and W. J. Kennington. 2009. Testing limits to adaptation along altitudinal gradients in rainforest Drosophila. Proceedings of the Royal Society B: Biological Sciences 276:1507-1515 -

$\rightarrow$ Bullock, J. M., R. J. Edwards, P. D. Carey, and R. J. Rose. 2000. Geographical separation of two Ulex species at three spatial scales $\rightarrow$ does competition limit species' ranges? Ecography 23:257-271.

$\rightarrow$ Carling, M. D., and R. T. Brumfield. 2007. Gene sampling strategie $\rightarrow$ for multi-locus population estimates of genetic diversity $(\theta)$. PLoS ONE 2:6.

$\rightarrow$ Case, T. J., and M. L. Taper. 2000. Interspecific competition, envi ronmental gradients, gene flow, and the coevolution of species' borders. American Naturalist 155:583-605.

Clausen, J. C., D. D. Keck, and W. M. Hiesey. 1948. Experimenta $\rightarrow$ Jen studies on the nature of species. III. Environment responses of climatic races of Achillea. Carnegie Institution of Washington Pub lication 581. Washington, DC.

$\rightarrow$ Cumming, G. S. 2002. Comparing climate and vegetation as limiting factors for species ranges of African ticks. Ecology 83:255-268.

$\rightarrow$ Daly, C. 2006. Guidelines for assessing the suitability of spatial climate data sets. International Journal of Climatology 26:707-721.

$\rightarrow$ Decker, J. P. 1958. Some effects of temperature and carbon dioxide concentration on photosynthesis of Mimulus. Plant Physiology $34 \rightarrow$ 103-106.

Drummond, A. J., B. Ashton, S. Buxton, M. Cheung, A. Cooper, J $\rightarrow$ Heled, M. Kearse, et al. 2009. Geneious. Version 4.8. http:// www.geneious.com.

$\rightarrow$ Eckert, C. G., K. E. Samis, and S. C. Lougheed. 2008. Genetic variation across species' geographical ranges: the central-marginal hypothesis and beyond. Molecular Ecology 17:1170-1188.

Excoffier, L., G. Laval, and S. Schneider. 2005. Arlequin ver. 3.0: an integrated software package for population genetics data analysis. Evolutionary Bioinformatics Online 1:47-50.

$\rightarrow$ Faubet, P., R. S. Waples, and O. E. Gaggiotti. 2007. Evaluating the performance of a multilocus Bayesian method for the estimation of migration rates. Molecular Ecology 16:1149-1166.

$\rightarrow$ Geber, M. A., and V. M. Eckhart. 2005. Experimental studies o $\rightarrow$ adaptation in Clarkia xantiana. II. Fitness variation across a subspecies border. Evolution 59:521-531.

$\rightarrow$ Goldberg, E. E., and R. Lande. 2007. Species' borders and dispersal barriers. American Naturalist 170:297-304.

$\rightarrow$ Griffith, T. M., and M. A. Watson. 2006. Is evolution necessary for range expansion? manipulating reproductive timing of a weedy annual transplanted beyond its range. American Naturalist 167: 153-164.

$\rightarrow$ Haldane, J. B. S. 1956. The relation between density regulation anc $\rightarrow$ natural selection. Proceedings of the Royal Society B: Biological Sciences 145:306-308.

Hickman, J. C. 1993. The Jepson manual: higher plants of California. University of California Press, Berkeley.

Hiesey, W. M., M. A. Nobs, and O. Björkman. 1971. Experimenta $\rightarrow$ studies on the nature of species. V. Biosystematics, genetics, and physiological ecology of the Erythranthe section of Mimulus. Carnegie Institute of Washington Publication 628. Washington, DC.

Holt, R. D., and M. Barfield. 2011. Theoretical perspectives on the statics and dynamics of species' borders in patchy environments. American Naturalist 178(suppl.):S6-S25.

Holt, R. D. 2003. On the evolutionary ecology of species' ranges. Evolutionary Ecology Research 5:159-178.

$\rightarrow$ Holt, R. D., and R. Gomulkiewicz. 1997. How does immigratior influence local adaptation? a reexamination of a familiar paradigm. American Naturalist 149:563-572.

Holt, R. D., and T. H. Keitt. 2000. Alternative causes for range limits: a metapopulation perspective. Ecology Letters 3:41-47.

. 2005. Species' borders: a unifying theme in ecology. Oikos 108:3-6.

Holt, R. D., T. M. Knight, and M. Barfield. 2004. Allee effects, immigration, and the evolution of species' niches. American Naturalist 163:253-262.

Holt, R. D., T. H. Keitt, M. A. Lewis, B. A. Maurer, and M. L. Taper. 2005. Theoretical models of species' borders: single species approaches. Oikos 108:18-27.

Jensen, J. L., A. J. Bohonak, and S. T. Kelley. 2005. Isolation by distance, Web service. BMC Genetics 6:13. http://ibdws.sdsu.edu/.

Katinas, L., and J. V. Crisci. 2008. Reconstructing the biogeographical history of two plant genera with different dispersion capabilities. Journal of Biogeography 35:1374-1384.

$\rightarrow$ Kawecki, T. J. 2008. Adaptation to marginal habitats. Annual Review of Ecology, Evolution, and Systematics 39:321-342.

$\rightarrow$ Kirkpatrick, M., and N. H. Barton. 1997. Evolution of a species range. American Naturalist 150:1-23.

Lennon, J. J., J. R. G. Turner, and D. Connell. 1997. A metapopulation model of species boundaries. Oikos 78:486-502.

Librado, P., and J. Rozas. 2009. DnaSP v5: a software for comprehensive analysis of DNA polymorphism data. Bioinformatics 25: 1451-1452.

Mayr, E. 1963. Animal species and evolution. Harvard University Press, Cambridge, MA.

Moeller, D. A., M. A. Geber, and P. Tiffin. 2011. Population genetics and the evolution of geographic range limits in an annual plant. American Naturalist 178(suppl.):S44-S57.

Paul, J. R., and S. J. Tonsor. 2008. Explaining geographic range size by species age: a test using Neotropical Piper species. Pages 4662 in W. P. Carson and S. Schnitzer, eds. Tropical forest community ecology. Blackwell, London.

Paul, J. R., C. Morton, C. M. Taylor, and S. J. Tonsor. 2009. Evolutionary time for dispersal limits the extent but not the occupancy of species' potential ranges in the tropical plant genus Psychotria (Rubiaceae). American Naturalist 173:188-199.

$\rightarrow$ Petit, R. J., S. Brewer, S. Bordacs, K. Burg, R. Cheddadi, E. Coart, J. Cottrell, et al. 2002. Identification of refugia and post-glacial colonisation routes of European white oaks based on chloroplast DNA and fossil pollen evidence. Forest Ecology and Management 156: 49-74.

Phillips, A. R. 1975. Migrations of Allen's and other hummingbirds. Condor 77:196-205.

$\rightarrow$ Pool, J. E., I. Hellmann, J. D. Jensen, and R. Nielsen. 2010. Population genetic inference from genomic sequence variation. Genome Research 20:291-300.

Price, T. D., and M. Kirkpatrick. 2009. Evolutionarily stable range limits set by interspecific competition. Proceedings of the Royal Society B: Biological Sciences 276:1429-1434.

Price, T. D., D. Mohan, D. T. Tietze, D. M. Hooper, C. D. L. Orme, and P. C. Rasmussen. 2011. Determinants of northerly range limits along the Himalayan bird diversity gradient. American Naturalist 178:S93-S104.

Rambaut, A., and A. J. Drummond. 2007. Tracer. Version 1.4. http://tree.bio.ed.ac.uk/software/tracer/.

Ramsey, J., H. D. Bradshaw, and D. W. Schemske. 2003. Components 
of reproductive isolation between the monkeyflowers Mimulus lew $\rightarrow$ Taniguchi, Y., and S. Nakano. 2000. Condition-specific competition: isii and M. cardinalis (Phrymaceae). Evolution 57:1520-1534. implications for the altitudinal distribution of stream fishes. Ecology 81:2027-2039.

$\rightarrow$ Randall, M. G. M. 1982. The dynamics of an insect population throughout its altitudinal distribution: Coleophora alticolella (Lep
idoptera) in northern England. Journal of Animal Ecology 51:9931016.

$\rightarrow$ Terborgh, J., and J. S. Weske. 1975. The role of competition in the distribution of Andean birds. Ecology 56:562-576.

R Development Core Team. 2008. R: a language and environment $\rightarrow$ Vucetich, J. A., and T. A. Waite. 2003. Spatial patterns of demography for statistical computing. R Foundation for Statistical Computing, Vienna. http://www.R-project.org. and genetic processes across the species' range: null hypotheses for landscape conservation genetics. Conservation Genetics 4:639645.

$\rightarrow$ Root, T. 1988. Environmental factors associated with avian distri $\rightarrow$ Wang, T., A. Hamann, D. L. Spittlehouse, and S. N. Aitken. 2006. butional boundaries. Journal of Biogeography 15:489-505.

$\rightarrow$ Sexton, J. P., P. J. McIntyre, A. L. Angert, and K. J. Rice. 2009. Evolution and ecology of species range limits. Annual Review of Ecology, Evolution, and Systematics 40:415-436. Development of scale-free climate data for western Canada for use in resource management. International Journal of Climatology 26: 383-397.

$\rightarrow$ Stephens, M., N. J. Smith, and P. Donnelly. 2001. A new statistical method for haplotype reconstruction from population data. American Journal of Human Genetics 68:978-989.

$\rightarrow$ Svenning, J. C., S. Normand, and F. Skov. 2008. Postglacial dispersal limitation of widespread forest plant species in nemoral Europe. Ecography 31:316-326.

$\rightarrow$ Szpiech, Z. A., M. Jakobsson, and N. A. Rosenberg. 2008. ADZE: a rarefaction approach for counting alleles private to combinations of populations. Bioinformatics 24:2498-2504.

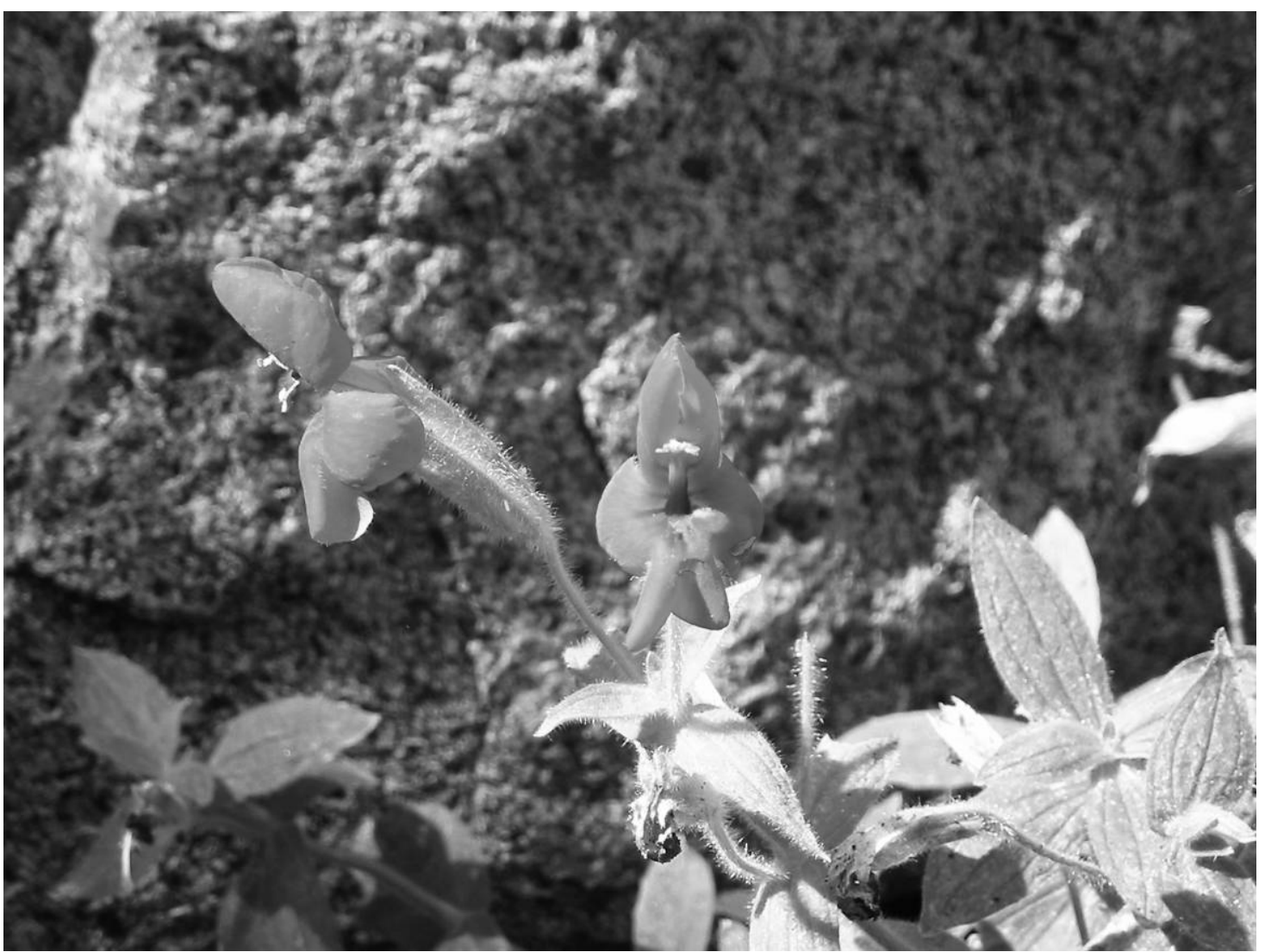

Flowering scarlet monkeyflower Mimulus cardinalis in the Sierra Nevada Mountains. Photograph by John Paul. 